\title{
MERAWAT KEBHINEKAAN MENJAGA KEINDONESIAAN: BELAJAR DARI NILAI KEBERAGAMAN DAN KEBERSATUAN MASYARAKAT PULAU
}

\author{
Endang Susilowati dan Noor Naelil Masruroh \\ Departemen Sejarah Fakultas Ilmu Budaya \\ Universitas Diponegoro
}

Alamat korespondensi: endangsusilowati@undip.ac.id

Diterima/ Received: 2 Maret 2018; Disetujui/ Accepted: 30 Maret 2018

\begin{abstract}
In the midst of the disintegration threat in Indonesia, efforts are needed to continuously maintain diversity. For that, there is nothing wrong if we take a look at the people life on the island that able to care for and maintain diversity. The Differences in race, ethnicity, religion, and culture do not lead to divisiveness but instead strengthen social harmony. Using historical approach, this article analyzes efforts to nurture diversity undertaken by nationals domiciled on the island. It specifies cases in two islands, the Natuna Islands, and the Karimunjawa Islands. Sociologically and culturally Indonesian society is indeed a plural society that has great potential for the emergence of conflicts and cleavage, if not based on multiculturalism. The people of Natuna and Karimunjawa are still able to maintain diversity and Indonesianness, so that they become example for other citizens, especially those who lived near with the government center, with various facilities but less able to maintain diversity.
\end{abstract}

Keywords: Pluralism; Multiculturalism; Social Harmony; Island Community.

\begin{abstract}
Abstrak
Di tengah-tengah ancaman disintegrasi yang dihadapi bangsa Indonesia, diperlukan upaya untuk terus menerus merawat keberagaman itu. Untuk itu, tidak ada salahnya bila kita menengok kehidupan masyarakat di pulau yang dapat merawat dan menjaga keberagaman. Perbedaan ras, suku bangsa, agama, dan budaya tidak menyebabkan keadaan terpecah belah, tetapi justru memperkuat harmoni sosial. Dengan menggunakan pendekatan historis, artikel ini bermaksud untuk menganalisis upaya-upaya merawat kebhinekaan yang dilakukan oleh warga bangsa yang berdomisili di pulau, dengan mengambil contoh kasus di dua kepulauan, yaitu Kepulauan Natuna dan Kepulauan Karimunjawa. Secara sosiologis dan kultural masyarakat Indonesia memang merupakan masyarakat plural yang memiliki potensi besar bagi munculnya konflik dan perpecahan, jika tidak dilandasi oleh multikulturalisme. Penduduk Natuna dan Karimunjawa yang memiliki keberagaman dalam etnik, agama, dan budaya ternyata tetap mampu merawat kebhinekaan dan menjaga keindonesiaan, sehingga bisa menjadi contoh bagi warga bangsa lain, terutama yang berada di dekat pusat pemerintahan dengan berbagai fasilitas, tetapi justru kurang mampu merawat dan menjaga kebhinekaan.
\end{abstract}

Kata Kunci: Pluralisme, Multikulturalisme, Harmoni Sosial, Masyarakat Kepulauan.

\section{PENDAHULUAN}

Sejak awal abad ke-20, ketika Indonesia masih berupa sebuah cita-cita, Tiga Serangkai (Eduard Douwes Dekker, dr. Tijpto Mangoenkoesoemo,
Ki Hadjar Dewantara) telah menegakkan cita-cita Republik yang mendalam bahwa Indonesia adalah untuk mereka yang bersedia dan ingin tinggal di dalamnya tanpa diskriminasi (Kusman, Kompas 19 Mei 2017). Hal itu berarti siapa pun 
yang bersedia dan ingin tinggal di Indonesia harus mau menerima perbedaan dan keberagaman yang mengiringi pembentukan bangsa ini menjadi Indonesia. Bagi bangsa Indonesia, multikulturalisme adalah suatu keniscayaan dan keharusan. Keragaman ras, suku, bahasa, budaya, dan agama merupakan ciri khas serta kelebihan bangsa Indonesia yang membedakannya dengan bangsa lain. Namun, akhir-akhir ini ada kecenderungan dari sebagian warga bangsa dan kelompok masyarakat untuk mengingkari sifat multikultur yang sudah melekat pada bangsa Indonesia sejak ratusan tahun lalu. Hal itu menyebabkan bangsa Indonesia kembali dihadapkan pada suatu situasi yang meresahkan, yaitu ancaman disintegrasi bangsa.

Sementara itu, perasaan yang mengikat kohesivitas persatuan masyarakat pulau adalah adanya rasa senasib sebagai satu bangsa. Nilai itu secara luas tidak hanya diyakini sebagai landasan filosofis bersama, tetapi juga merupakan reaksi politis (Conversi, 2007: 73). Oleh karena itu, nasionalisme mencakup tiga proposisi antara lain; (1) Identitas nasional yang benar-benar merupakan bagian dari identitas pribadi; (2) Adanya kewajiban yang terbatas kepada sesama warga negara; (3) Adanya klaim penentuan nasib sendiri secara politik (Conversi, 2007: 75). Memiliki identitas nasional berarti menganggap diri sebagai milik sebuah komunitas yang dibentuk oleh kepercayaan bersama, berada dalam satu cerita sejarah yang sama, bersifat aktif, terhubung dengan wilayah tertentu, dan ditandai dengan sifat yang khas oleh para anggotanya.

Secara sosiologis dan kultural masyarakat Indonesia memang merupakan masyarakat plural yang memiliki potensi besar bagi munculnya konflik dan perpecahan jika tidak dilandasi oleh multikulturalisme. Konsep ini serupa dengan "Bhinneka Tunggal Ika" (Sulistiyono, 2015: 2). Meskipun masyarakat Indonesia merupakan masyarakat yang pluralistik dari sisi ras, etnis, bahasa, status sosial, kepercayaan, dan sebagainya, namun merupakan suatu kesatuan guna mencapai tujuan bersama dalam konteks Negara Kesatuan Republik Indonesia (NKRI) yang berdasar Pancasila dan UUD 1945. Paradigma multikulturalisme yang menekankan dialog, toleransi, dan kesediaan untuk koeksistensi dalam keberagaman sesuai dengan salah satu pilar kebangsaan Indonesia, yaitu Bhinneka Tunggal Ika (Sulistiyono, 2015: 17).

Namun demikian, seperti yang diungkap oleh Latif (2011) mengupayakan persatuan masyarakat plural seperti Indonesia bukan hal mudah. Proses pembentukan dan penguatan nation bulding merupakan agenda penting yang harus dibina dan ditumbuhkan. Usaha untuk merajut karakter, kehendak, dan komitmen bersama dari suatu bangsa majemuk mensyaratkan hadirnya negara persatuan seperti yang tercermin dalam bagian akhir pidato Soekarno pada 1 Juni 1945 (Latif, 2011: 370372). Negara persatuan Indonesia merupakan ekspresi dan pendorong semangat kegotongroyongan, untuk mewujudkannya maka perlu diperkuat dengan budaya gotong royong dalam kehidupan masyarakat sipil dan politik dengan mengembangkan pendidikan kewargaan dan multikulturalisme yang mampu membangun rasa keadilan dan kebersamaan.

Bangsa Indonesia yang terdiri dari berbagai suku, agama, ras, budaya, dan bahasa sudah sejak dulu memiliki sikap saling menghormati. Hal itu telah terbukti dengan kelahiran Sumpah Pemuda pada 28 Oktober 1928. Namun saat ini bangsa Indonesia sedang diuji kedewasaan dan keragamannya dengan maraknya kasus intoleransi dan berbagai kasus SARA. Salah satu perekat nasionalisme adalah kebhinekaan. Sayang semboyan Bhinneka Tunggal Ika yang diagungkan dan digaungkan sejak dahulu oleh para pendiri bangsa, tampaknya mulai tidak dipahami dan hanya sebatas ucapan (https: //suaradewata.com/read/2017/01/06/201701 060003/Nilai-nilai-Kebhinekaan-Dalam-Multi kulturalisme-dan-Ancamannya.html, dikunjungi pada 20 Oktober 2017).

Dalam konteks Indonesia, sebagai salah satu representasi keberagaman mayarakat dapat dilihat pada proses dan dampak dari berbagai gejolak sosiokultural dan politik yang terjadi. Adanya konflik sektoral dan horizontal mengancam cita-cita kebhinekaan, dan keberagaman bangsa Indonesia (Purwanto, 2012: 5).

Artikel ini bertujuan untuk merefleksikan upaya-upaya merawat kebhinekaan yang 
dilakukan oleh warga bangsa yang berdomisili di pulau, dengan mengambil contoh kasus di dua kepulauan, yaitu Kepulauan Natuna dan Kepulauan Karimunjawa. Penduduk Natuna dan Karimunjawa yang memiliki keberagaman dalam etnik, agama, dan budaya ternyata tetap mampu merawat kebhinekaan dan menjaga keindonesiaan, sehingga bisa menjadi contoh bagi warga bangsa lain, terutama yang berada di dekat pusat pemerintahan dengan berbagai fasilitas, tetapi justru kurang mampu merawat dan menjaga kebhinekaan.

Sebagai refleksi atas kuatnya rasa kebangsaan dan kebhinekaan masyarakat kepulauan, maka perlu dipetakan gambaran mengenai sejarah singkat Natuna sejak awal terbentuknya menurut tradisi lisan hingga menjadi sebuah daerah otonom berupa kabupaten yang merupakan hasil pemekaran dari Kabupaten Kepulauan Riau, hingga gambaran mengenai profil kekinian Kabupaten Natuna. Selain itu, upaya untuk menggali nilai-nilai keberagaman di Kepulauan Karimunjawa dilakukan melalui identifikasi nilai-nilai kultural dan tradisi yang masih berlaku dalam masyarakat, serta potret nasionalisme masyarakat yang diperoleh dari hasil wawancara dengan para tokoh formal, tokoh informal, dan tokoh pemuda.

\section{GEOGRAFIS DAN DEMOGRAFIS}

\section{Kepulauan Natuna}

Kepulauan Natuna adalah salah satu gugusan kepulauan terdepan yang wilayahnya berbatasan perairan dengan beberapa negara tetangga seperti Malaysia, Singapura, Brunei Darussalam, Thailand, dan Vietnam. Natuna juga merupakan beranda terdepan Indonesia yang berada pada jalur pelayaran internasional Hongkong, Jepang, Korea, dan Taiwan, sehingga banyak dilalui dan disinggahi oleh kapal-kapal dari berbagai negara (Susilowati, dkk. 2013: 25). Apalagi kekayaan alam Natuna yang melimpah, terutama sumber daya hayati laut dan gas bumi, telah mengundang banyak bangsa lain untuk datang ke Natuna. Semua itu tentu merupakan anugerah bagi warga Natuna khususnya dan bangsa Indonesia pada umumnya, tetapi sekaligus juga dapat menjadi ancaman bagi persatuan dan kesatuan warga bangsa.

Pulau Natuna secara administratif merupakan bagian dari Kabupaten Natuna, Provinsi Kepulauan Riau. Pulau Natuna (disebut juga Pulau Bunguran) merupakan pulau terbesar di antara 157 pulau yang membentuk Kabupaten Natuna. Di antara 157 pulau tersebut hanya 30 pulau yang berpenghuni, sisanya merupakan pulau-pulau kosong. Dari 30 pulau yang berpenghuni, jumlah penduduk terbesar ada di pulau Bunguran, yaitu sebanyak 50.019 jiwa dari keseluruhan jumlah penduduk Kabupaten Natuna yang berjumlah 72.950 jiwa pada tahun 2011 (BPS Kab. Natuna, 2012: 77). Pada tahun 2015 jumlah penduduk Kabupaten Natuna meningkat menjadi 74.520 jiwa yang terdiri dari 38.420 penduduk laki-laki dan 36.110 penduduk perempuan (BPS Kab. Natuna, 2016: 5). Terjadinya peningkatan jumlah penduduk di Kabupaten Natuna saat ini didukung oleh arus migrasi orang dan barang. Sebagai wilayah kepulauan dengan perkembangan daerah pesisir yang relatif cepat, migrasi dan mobilitas sosial merupakan salah satu ciri penting. Selain para pedagang, transmigran terbesar di Natuna adalah orang-orang Jawa yang mengikuti program transmigrasi sejak dekade 1970-an.

Penduduk Natuna sebagian besar adalah etnis Melayu yang dapat dikatakan merupakan penduduk asli dan tersebar di seluruh penjuru Natuna. Di samping etnis Melayu, di Natuna juga terdapat etnis Jawa, Minang, Batak, Bugis, dan lain-lain. Komposisi penduduk Natuna dapat digambarkan sebagai berikut: Melayu (80\%), Jawa (11\%), Minang (3\%), Batak (2\%), Bugis, Sunda, Dayak (masing-masing 1\%), serta Banjar dan Sulawesi lainnya (1\%) (Susilowati, dkk., 2015: 29). Menurut Ketua Lembaga Adat Melayu (LAM), Wan Zawali, penduduk Melayu menerima keberadaan suku lain di tanah Melayu dengan tangan terbuka. Oleh karena itu, hingga saat ini tidak terjadi konflik antar suku di tengahtengah penduduk Natuna. Agama yang dianut oleh penduduk Natuna juga beragam. Pemeluk agama Islam sebanyak 77,5\%, Kristen Protestan 6,20\%, Katholik 1,27\%, Hindu 0,03\%, Budha $14,8 \%$, dan Konghuchu sebanyak 0,07\% (Susilowati, dkk., 2015: 30). Kerukunan 
antarumat beragama di Natuna sangat terasa. Hal itu antara lain terlihat dari bangunan tempat ibadah yang letaknya berdampingan, masjid dibangun berdampingan dengan kelenteng dan gereja bersebelahan dengan masjid.

\section{Kepulauan Karimunjawa}

Karimunjawa merupakan gugusan kepulauan yang terletak di Laut Jawa dan hanya berjarak kurang lebih $83 \mathrm{~km}$ (45 mil laut) dari Jepara. Secara administratif Karimunjawa adalah sebuah kecamatan yang berada di bawah Kabupaten Jepara, Provinsi Jawa Tengah. Kepulauan Karimunjawa dibentuk oleh 27 pulau, tetapi hanya lima pulau saja yang berpenduduk, yaitu Pulau Karimunjawa, Kemojan, Parang, Nyamuk, dan Genting. Tidak berbeda dengan Natuna, Karimunjawa juga memiliki keragaman etnis, agama, dan budaya. Pada tahun 2016, jumlah penduduk Karimunjawa adalah sebanyak 9.373 jiwa yang terdiri dari 4.728 laki-laki dan 4.651 perempuan (BPS Kab. Jepara, 2016). Penduduk Karimunjawa meliputi etnis Jawa, Bugis, Madura, Sunda, Batak, dan Bajo. Etnis Jawa menduduki jumlah terbesar (81\%), disusul etnis Bugis (8,5\%), Madura (7\%), Sunda (1,6\%), Batak (1\%), dan etnis lainnya $(0,9 \%)$ (Suliyati dkk., 2016: 2).

\section{MERAWAT KEBHINEKAAN DAN MENJAGA KEINDONESIAAN DI KEPULAUAN NATUNA}

Kondisi masyarakat Natuna yang multiras, multietnik, dan multiagama, tidak menjadi kendala untuk membina kerukunan masyarakat, baik dalam bidang ekonomi, sosial, maupun budaya. Etnis pendatang secara cepat dan mudah dapat beradaptasi dengan budaya masyarakat Melayu. Hal itu hanya dimungkinkan bila etnis mayoritas yang merupakan penduduk asli bersikap terbuka dan mengembangkan multikulturalisme yang akomodatif (https:// tomisapari.blogspot.co.id/2013/03/jenis-jenismultikulturalisme.html, diakses pada 26 Januari 2018). Tampaknya para tokoh agama, tokoh masyarakat, dan para pendidik di Natuna mengajarkan, mempraktikkan, dan mengarti kulasikan multikulturalisme akomodatif dalam kehidupan sehari-hari. Meskipun pola pemukiman penduduk Natuna masih terlihat mengelompok secara etnis (Susilowati dkk., 2015: 30), namun hal itu tidak menjadi kendala untuk saling berinteraksi dan membina kerukunan antaretnis dan antaragama (Kusman, Kompas 19 Mei 2017).

Satu hal yang tidak dapat dipisahkan dari sikap kebhinekaan masyarakat Natuna adalah kecintaan yang mendalam pada tanah air, negara, dan bangsanya, Indonesia. Kesetiaan dan kecintaan pada negara itu antara lain terlihat dari semboyan "NKRI Harga Mati" yang digaungkan di sekolah-sekolah. Meskipun letak Natuna sangat jauh dari pusat pemerintahan Indonesia dan lebih dekat dengan negara tetangga (1.135,629 km dari Jakarta, tetapi hanya 581,565 $\mathrm{km}$ dari Singapura dan 350,037 km dari Kuching, Malaysia) (BPS Kabupaten Natuna, 2012: 18), namun warga masyarakat Natuna tidak tergiur untuk memalingkan muka dari tanah airnya demi mendapat kehidupan yang jauh lebih baik di negeri orang. Jarak yang sangat jauh dari pusat pemerintahan serta sarana transportasi yang belum memadai dan terjangkau oleh segenap lapisan masyarakat, sebenarnya memberi peluang kepada warga Natuna (apabila mereka mau) untuk menjadi warga negara lain, misal Malaysia. Kesempatan dan peluang itu jelas ada, tetapi hampir tidak ada warga Natuna yang ingin meninggalkan tanah airnya untuk menjadi warga dari negara lain.

Kedekatan jarak antara Natuna dengan Malaysia dan Singapura memang telah membuat Natuna menjadi pasar bagi barang-barang produksi dari kedua negara tersbut, baik berupa barang konsumsi maupun barang kebutuhan lainnya. Pasar Natuna dibanjiri oleh barangbarang kebutuhan sehari-hari dari Malaysia dan Singapura. Harga barang-barang kebutuhan tersebut bahkan lebih murah dibanding dengan harga barang-barang yang didatangkan dari wilayah Indonesia sendiri. Jarak yang cukup jauh dan sarana transportasi yang kurang memadai (antara lain dilayani oleh kapal perintis yang datang di pelabuhan Penagi/Ranai hanya setiap 13 hari sekali) menyebabkan barang kebutuhan sehari-hari tidak selalu tersedia, sehingga harga 
barang di tingkat konsumen menjadi lebih mahal. Oleh karena itu wajar bila dalam kehidupan sehari-hari penduduk Natuna lebih memilih untuk mengonsumsi barang-barang dari luar, yang notabene selalu ada di pasaran dengan harga terjangkau. Keadaan seperti itu tentu bukan cerminan lunturnya rasa kebangsaan, tetapi merupakan suatu upaya untuk menyikapi keadaan tanpa harus banyak protes pada pemerintah.

Upaya untuk memahami nasionalisme di wilayah perbatasan seperti Natuna menjadi relevan mengingat batas-batas negara poskolonial pada umumnya tidak hanya membelah etnisitas yang berbeda, tetapi juga membelah etnik yang sama karena sejarah kebangsaan yang berbeda dimiliki warga etnis yang sama. Walaupun berbatasan wilayah laut dengan beberapa negara, melakukan aktivitas ekonomi dengan warga negara tetangga, dan banyak menggunakan produk-produk luar negeri khususnya Malaysia dalam pemenuhan kehidupan sehari-hari, tampaknya belum ada persoalan yang cukup serius berkaitan dengan nasionalisme masyarakat Kabupaten Natuna. Setidaknya hal ini tercermin dengan adanya slogan yang berbunyi "NKRI Harga Mati” yang terdapat di lingkungan Sekolah Menengah Kejuruan (SMK) 1 Kabupaten Natuna. Keberadaan slogan itu merefleksikan adanya keinginan yang tidak dapat ditawar-tawar lagi dari sebagian masyarakat Kabupaten Natuna untuk tetap menjadi bagian dari Negara Kesatuan Republik Indonesia, sekaligus merupakan upaya untuk menanamkan rasa kebangsaan dan cinta tanah air kepada siapa yang membacanya, khususnya siswa-siswi SMK Kelautan.

Namun demikian, adanya solusi-solusi untuk meningkatkan kemajuan dan kesejahteraan masyarakat Natuna, penanaman nilai-nilai nasionalisme tehadap masyarakat Natuna tetap harus dilakukan, agar nasionalisme mereka tidak mengalami kemerosotan, yang kemudian mampu berdampak pada upaya disintegrasi nasional. Penanaman nasionalisme perlu dilakukan melalui jalur pendidikan. Pendidikan dari jenjang sekolah dasar sampai dengan Sekolah Menengah Atas (SMA) harus memberikan perhatian yang cukup terhadap penanaman nilai-nilai nasionalisme. Guru memiliki peran penting dalam penanaman nilai-nilai nasionalisme. Nasionalisme harus tetap dipertahankan, ditumbuhkembangkan, dan dipelihara di kalangan masyarakat Natuna.

\section{MENJAGA NILAI-NILAI KEBHINEKAAN DI KEPULAUAN KARIMUNJAWA}

Masyarakat Karimunjawa terbentuk melalui proses migrasi. Penduduk pada awalnya merupakan suku-suku pendatang. Mereka adalah para perantau yang berusaha mengadu nasib di pulau yang mereka singgahi. Jadi tidak ada suku bangsa asli Karimunjawa. Hal itu sangat dimungkinkan mengingat posisi Kepulauan Karimunjawa berada di antara Pulau Jawa dan Pulau Kalimantan, sehingga menjadi tempat persinggahan dan peristirahatan bagi para pelaut dan pedagang yang sedang melakukan perdagangan di pantai utara Jawa atau perdagangan antarpulau. Keberagaman etnis di Karimunjawa merupakan suatu kondisi kultural yang bila tidak terkelola dengan baik dapat mengganggu proses kohesivitas sosial dan integrasi masyarakat sebagai fondasi bagi terciptanya integrasi nasional (Suliyati, dkk., 2017: 306).

Masyarakat Karimunjawa yang multikultur ternyata merupakan suatu perpaduan yang harmonis. Waktu telah membuktikan bahwa keberagaman dalam masyarakat Karimunjawa justru menjadi potensi yang menguatkan. Kerelaan untuk saling menerima kehadiran kelompok atau suku lain dengan keragaman agama dan budaya yang melekat, menunjukkan bahwa masyarakat Karimunjawa sangat menjaga nilai-nilai kebhinekaan. Dalam hal ini tiga suku utama (Jawa, Bugis, Madura) yang dapat dikatakan merupakan pembentuk awal masyarakat Karimunjawa mempunyai peran penting. Koeksistensi yang mereka lakukan telah menyemai kedamaian dan kerukunan. Meskipun mereka memiliki perbedaan latar belakang suku dan budaya, tetapi mereka dapat mewujudkan hubungan sosial yang baik, sehingga tidak pernah terjadi konflik yang mengganggu harmoni sosial dalam masyarakat Karimunjawa (Suliyati, dkk., 2017: 304). Hal itu menunjukkan bahwa masyarakat Karimunjawa mempunyai kesadaran sosial yang tinggi dan keterbukaan untuk 
menerima perbedaan. Dengan kata lain mereka telah dapat mepraksiskan multikulturalisme dalam kehidupan sehari-hari.

Esensi pluralisme tampak nyata dalam kehidupan dan keseharian masyarakat di Karimunjawa. Berbagai etnis yang hidup di Karimunjawa secara proporsional saling memberikan penghargaan dan pengakuan terhadap kegiatan, nilai-nilai sosial, struktur sosial atau organisasi masyarakat serta sistem gagasan yang beraneka ragam. Masyarakat Karimunjawa sejak awal sudah menerima keberagaman di lingkungan mereka, karena keberagaman mengandung nilai-nilai kemanusiaan yang bertujuan untuk menciptakan kehidupan yang harmonis dan sejahtera (Suliyati, dkk., 2016: 37).

\section{BELAJAR DARI MASYARAKAT PULAU}

Terjaganya kerukunan antaretnis dan antaragama seperti terlihat di Natuna dan Karimunjawa tentu merupakan suatu keniscayaan. Masyarakat di kedua kepulauan tersebut telah mampu menunjukkan gambaran rapi tentang aneka budaya yang sebenarnya terpisah-pisah. Menurut Adrian Vickers, di balik gambaran rapi tentang aneka budaya yang terpisah-pisah itu bersemayam suatu prinsip interaksi dinamis, atau pergerakan aktif heterogenitas, yang dapat diringkas dalam istilah peradaban pesisir atau peradaban daerah pantai (Vickers, 2009: 1). Istilah peradaban pesisir memang digunakan oleh Vickers dalam konteks masyarakat Asia Tenggara, tetapi kiranya dapat pula diterapkan dalam konteks masyarakat pulau seperti masyarakat Natuna dan Karimunjawa. Hal itu tidak lain karena konsep peradaban sebenarnya mencakup apa yang dipahami sebagai budaya, masyarakat, atau negara. Peradaban juga menerabas definisi-definisi religius, namun memberikan kesadaran tentang sebuah dunia berwawasan tatanan yang merangkul beragam corak (Vickers, 2009: 1; Sulistiyono, 2015: 8). Barangkali dalam konteks ini dapat dipahami konsep kebhinekaan sebagaimana dipraksiskan oleh masyarakat Natuna dan Karimunjawa.

Sikap egaliter, terbuka, toleran, dan mudah menerima kehadiran orang lain merupakan modal dasar bagi masyarakat pesisir dan pulau dengan keberagaman di berbagai bidang, untuk membina hubungan sosial, ekonomi, dan budaya yang harmonis dengan kelompok-kelompok masyarakat lainnya. Mereka telah menunjukkan kepada kita bahwa keberagaman dan perbedaan tidak perlu dipertentangkan, tetapi justru harus dikelola dengan baik sehingga dapat menjadi kekuatan bersama. Jadi, tidak ada salahnya bila kita mau membuka diri dan bersedia belajar dari mereka.

\section{SIMPULAN}

Dengan kondisi geografis yang terdiri atas ribuan pulau dan luas laut dengan keragaman masyarakat suku bangsa dan kebudayaannya, Negara Kesatuan Republik Indonesia (NKRI) dihadapkan pada masalah integrasi nasional yang berat dan rumit (Zuhdi, 2014: 103).

Keberagaman dalam berbagai aspek kehidupan adalah takdir bagi bangsa Indonesia yang tidak mungkin dihindari. Hal itu justru merupakan anugerah yang harus disyukuri. Namun, perbedaan dan keberbedaan itu harus dikelola dengan baik sehingga tidak menjadi sumber perselisihan, konflik, dan kekerasan. Oleh karena itu, harus ada formula pemahaman yang tepat-guna mendamaikan dan menyatukannya (Syahrazad, Kompas 6 April 2017). Sementara itu, salah satu aspek dari upaya merawat kebhinekaan adalah adanya perasaan bangga terhadap jati diri bangsa. Kebanggaan nasional dianggap sebagai konsekuensi logis atas keberhasilan negara dalam menyelenggarakan pembangunan nasional untuk memenuhi kesejahteraan masyarakat (Pamungkas, 2015: 151-152).

Penghormatan atas kebhinekaan dengan kesadaran merawatnya merupakan energi hidup bagi sebuah bangsa. Dengan penghormatan atas keragaman sosial, bangsa Indonesia akan memiliki perekat sosial yang membuat setiap warga bangsa yang ada di dalamnya masih memiliki kehendak untuk menjadi satu sebagai bagian dari keindonesiaan. Dalam hal ini komitmen seluruh warga bangsa dan kehadiran negara sangat diperlukan. 


\section{REFERENSI}

Kusman, A.P. (2017). "Bangsa yang Menghormati Kebinekaan”, Kompas, 19 Mei.

BPS Kabupaten Jepara. Jepara dalam Angka 2016.

BPS Kabupaten Natuna. Natuna dalam Angka 2012.

Conversi, D. (2007). "Homogenisation, Nationalism and War: Should We Still Read Ernest Gellner?" Nations and Nationalism, Vol. 13 (3): 371-394.

http: //suaradewata.com/read/2017/01/06/ 201701060003/Nilainilai-KebhinekaanDalam-Multikulturalisme-danAncamannya.html, dikunjungi pada 20 Oktober 2017.

https://tomisapari.blogspot.co.id/2013/03/ jenis-jenis-multikulturalisme.html, dikunjungi pada 21 Januari 2018.

Latif, Y. (2016). Negara Paripurna. Jakarta: Gramedia Pustaka Utama.

Pamungkas, C. (2015). "Nasionalisme Masyarakat di Perbatasan Laut: Studi Kasus Masyarakat Nelayan Karimun", Masyarakat Indonesia, Vol. 41 (2): 147162.

Purwanto, B. (2012). "Merajut Kebhinekaan dan Kearifan Budaya bagi Kemajuan dan Kesejahteraan Indonesia”. Pidato Ilmiah Dalam Rangka Peringatan Dies Natalis ke-63.

Syahrazad, H. "Indonesia dan Akomodasi Multikultural”, Kompas, 6 April 2017.

Sulistiyono, S. T. (2015). "Multikulturalisme dalam Perspektif Budaya Pesisir”, Jurnal Agastya, Vol. 5 (1): 1-18.

Suliyati, T. dkk. (2016). "Pola-Pola Interaksi Sosial pada Masyarakat Plural: Studi Kasus Masyarakat Maritim Di Karimunjawa”. Laporan Penelitian Riset Pengembangan dan Penerapan. Lembaga Penelitian dan Pengabdian pada Masyarakat Universitas Diponegoro.

Suliyati, T. Rochwulaningsih, Y., Utama, M. P. (2017). "Interetnic Interaction Pattern in Karimunjawa Island”, Komunitas:
International Journal of Indonesian Society and Culture, Vol. 9 (2):302-310. Susilowati, E., dkk. (2013). "Model Pananaman Nilai-nilai Nasionalisme pada Masyarakat Pulau Terluar (Studi Kasus Kabupaten Natuna)". Laporan Penelitian Strategis Nasional, DP2M DIKTI.

Susilowati, E., Dhanang Respati Puguh, dan Noor Naeilil Masruroh (2015). "Penanaman Nilai-Nilai Nasionalisme di Kepulauan Natuna", Humanika, Vol. 19 No.1: 158170.

Vickers, A. (2009). Peradaban Pesisir: Menuju Sejarah Budaya Asia Tenggara. Denpasar: Pustaka Larasan-Udayana University Press.

Zuhdi, S. (2014). Nasionalisme, Laut, dan Sejarah. Depok: Komunitas Bambu. 